\title{
Aspectos semânticos dos verbos cognitivos deduzir e calcular no português
}

DOI: http://dx.doi.org/10.21165/el.v48i2.2199

\section{Letícia de Almeida Barbosa-Santos \\ Solange de Carvalho Fortilli ${ }^{2}$}

\section{Resumo}

Este trabalho analisa os verbos cognitivos deduzir e calcular, a fim de identificar, dentre as acepções que os compõem, aquelas que se salientam em sua atuação como parênteses. Os aspectos teóricos relacionam-se à Gramaticalização (HEINE; CLAUDI; HUNNEMEYER 1991; HOPPER; TRAUGOTT, 1993; HIMMELMANN, 2004), e em trabalhos sobre a parentetização de verbos (GONÇALVES, 2003; CASSEB-GALVÃO, 2000; FORTILLI, 2015), associada ao comportamento semelhante ao de advérbios. Utilizaram-se ocorrências entre os séculos XIX a XXI, do Corpus do Português e do jornal Folha.com. Por meio da análise, são apresentados seus vários significados, delineando-se aqueles que os mantêm mais arraigados à expressão de mecanismos de cognição, exprimindo processos mentais específicos, e os que sustentam sua atuação como modais epistêmicos.

Palavras-chave: verbos cognitivos; gramaticalização; parentetização.

\footnotetext{
1 Universidade Estadual Paulista "Júlio de Mesquita Filho" (UNESP), São José do Rio Preto, São Paulo, Brasil; leticiaalmeidabarboza@gmail.com; https://orcid.org/0000-0001-9386-8199

2 Universidade Federal de Mato Grosso do Sul (UFMS), Três Lagoas, Mato Grosso do Sul, Brasil; fortilli@gmail.com; https://orcid.org/0000-0002-8348-4359
} 


\title{
Semantic aspects of the cognitive verbs deduzir and calcular in Portuguese
}

\begin{abstract}
This paper analyzes the cognitive verbs deduzir and calcular, in order to identify those that stand out in their acting as parentheses among the meanings that compose them. Theoretical aspects are related to Grammaticalization (HEINE, CLAUDI E HUNNEMEYER, 1991; HOPPER, TRAUGOTT, 1993; HIMMELMANN, 2004), and in specific works on the parenthetization of verbs (GONÇALVES, 2003; CASSEB-GALVÃO, 2000; FORTILLI, 2015), associated to its behavior that is similar to adverbs. Occurrences between the $19^{\text {th }}$ and $21^{\text {st }}$ centuries, from the Corpus do Português and Folha.com were used. By means of studies on the semantics of these verbs, their various meanings are presented, outlining those that hold them more deeply rooted in the expression of mechanisms of cognition, expressing specific mental processes, and those that support their performance as epistemic modalities.
\end{abstract}

Keywords: cognitive verbs; grammaticalization; parenthetization.

\section{Considerações iniciais}

Os verbos de cognição expressam processos mentais relacionados a raciocínios, percepções e conhecimentos do falante e podem, também, exprimir crenças e posicionamentos diante de um conteúdo. Para Halliday (1985), os verbos de cognição alocam-se no âmbito dos verbos de processos mentais, os quais, por desempenharem uma ação na mente, não apresentam evidência no mundo biofísico.

O grupo dos verbos cognitivos, segundo Halliday (1985), encontra-se subdividido em: de processos mentais de percepção, expressos por verbos como ouvir, ver e sentir; processos mentais de afeição, como amar e gostar, e processos mentais de cognição, tais como entender, achar, lembrar, esquecer e planejar, intimamente ligados à crença e à memória. Neste estudo, serão analisados os verbos que se enquadram no terceiro conjunto, que abarca, também, achar, acreditar, calcular, crer, deduzir, imaginar, reconhecer, somar, supor e muitos outros. Nota-se que, dentre tantos, há aqueles que denotam, de fato, um mecanismo de cognição e os que se destacam pelas suas acepções mais abstratas, ligadas à expressão do grau de conhecimento do falante e sua postura diante de uma informação.

Tipicamente, esses verbos são encaixadores de orações completivas, sendo, portanto, predicados matrizes, enquanto a oração que o contém é a oração matriz. Para além do uso típico como encaixador, nota-se, em contextos reais de comunicação, que tais verbos têm apresentado outro funcionamento, pois passam de predicados matrizes a parentéticos epistêmicos, caracterizados como unidades independentes da sentença, 
que têm como domínio o enunciado todo ou parte dele e, funcionalmente, um valor mais subjetivo.

Segundo Schneider (2007, p. 2), expressões parentéticas "não são nem a cláusula principal nem uma cláusula subordinada, mas inserções anexadas ao final da frase, de maneira semelhante aos advérbios". Juntamente com essa alteração de perfil sintático, os verbos passam por modificações relativas às suas acepções, uma vez que, quando se parentetizam, experimentam a supressão de seus significados mais voltados à expressão de um processo mental específico. Ao se parentetizar, há a saliência de sua função como modalizador, com fortalecimento da marcação de atitude e crença do falante diante do conteúdo proposicional. Com calcular, por exemplo, tem-se a seguinte ocorrência:

(1). Quem é que quer se apaixonar por uma pessoa que não corresponde a esse amor, estando ainda a recompor-se de uma separação recente?? Ninguém (calculo eu)...ninguém gosta de sofrer! (portaldoamor.com.br)

É notável que calculo, nesse tipo de uso, não tonifica suas acepções mais específicas, ligadas a uma quantificação originada de raciocínio matemático. Assim, entrelaçando a parentetização desses verbos e sua atuação como elementos adverbiais, estatuto que toca o processo de Gramaticalização (doravante GR), surge o interesse de detalhar a significação de deduzir e calcular para explicar como interagem suas acepções até que eles possam atuar expressando fortemente modalidade epistêmica, considerada como um âmbito mais abstrato do que aquele que denota um processamento quantitativo.

Desse modo, os objetivos desse trabalho são: i) elencar e analisar acepções presentes em calcular e deduzir, ii) identificar, pela interação entre elas, quais se tonificam quando esses dois verbos passam por parentetização e iii) salientar os aspectos que diferenciam esses dois verbos de outros cognitivos que, mesmo semelhantes a eles, não se parentetizam. Evidencia-se, aqui, que o perfil desses parentéticos epistêmicos revela abstratização e generalização de significados, possibilitando ainda mais sua associação à GR. Trabalhos como os de Casseb-Galvão (1999, 2000), Gonçalves $(2003,2004)$ e Fortilli (2015) mostram um conjunto de verbos cognitivos candidatos à metaforização e à abstratização de significados, trilhando caminho semelhante quanto às mudanças semânticas possíveis em casos de GR.

Para a discussão, selecionaram-se ocorrências dos séculos $X I X, X X$ e $X X I$, no Corpus do Português (DAVIES; FERREIRA, 2006), disponível on-line em https://www. corpusdoportugues.org/, e composto por mais de 45 milhões de palavras, em milhares de enunciados de diferentes registros e gêneros, do Brasil e de Portugal. Este corpus apresenta ocorrências dos séculos XIV a XXI, mas optou-se por contemplar apenas o português mais atual. A busca foi por ocorrências com deduzir e calcular encaixando 
orações e, posteriormente, por dados com esses dois verbos parentetizados, sem atribuir relevância às frequências.

Este artigo organiza-se da seguinte forma: de início, são apresentados os aportes teóricos utilizados na investigação; em um segundo momento, são apresentadas as análises, pautadas nas matrizes semânticas dos verbos deduzir e calcular e, para encerrar, são tecidas as considerações finais.

\section{Fundamentação teórica}

Ancorados na definição clássica de gramaticalização, de Meillet (1912)³, Hopper e Traugott (1993) mostram que as pressões relativas à expressividade dos vocábulos desencadeiam tal processo, permitindo que itens lexicais passem, com o tempo, a desempenhar funções gramaticais e itens gramaticais aumentem ainda mais a sua gramaticalidade, o que mostra que a gramática é afetada pela mudança linguística.

Observa-se, por meio dos diferentes processos de GR, que a trajetória de abstratização é constantemente influenciada por mecanismos de ordem semântica, tais como, a metaforização, que proporciona a extensão de significados, a generalização, que possibilita um maior alcance contextual, devido às transformações em significados específicos. Assim, possibilita-se que autores, em estudos mais atuais, como os de Himmelmann (2004) ${ }^{4}$ entendam GR como uma trajetória de expansão, uma vez que são ampliados os contextos sintáticos, semânticos e pragmáticos de um determinado elemento.

Considerando que o processo de GR pode ser concebido como expansão semânticopragmática, nota-se que, durante o processo, há atuação de diversos mecanismos de ordem cognitiva, tais como, metáfora, metonímia, generalização e abstratização. Bybee (1994) mostra alguns mecanismos que proporcionam a inespecificidade dos significados e o aumento das possibilidades de uso. A extensão metafórica e a generalização de significados são consideradas indícios de uma trajetória de mudança, uma vez que, ao passar por metaforização, acepções de domínios concretos são acionadas para representação de um novo uso, mais abstrato. E, ao ocorrer generalização, significados específicos do elemento enfraquecem-se e, em decorrência disso, ele pode ocorrer em mais situações, aumentando sua frequência.

3 Em Meillet (1912), a gramaticalização caracterizou-se como um fenômeno que permite a atribuição de um caráter gramatical a uma palavra autônoma, via processo diacrônico.

4 Para o autor, "semantic-pragmatic context expansion is the core defining feature of grammaticalization process" (HIMMELMANN, 2004, p. 33). 
Observa-se, em Bybee (1994, p. 290), o processo de generalização do verbo can, do inglês:

Quadro 1. A generalização do verbo can

Can

mental ability (i) mental enabling conditions exist in an agent for the completion of the predicate situation.

general ability (ii) enabling conditions exist in an agent for the completion of the predicate situation.

root possibility (iii) enabling conditions exist for the completion of the predicate situation.

Fonte: Bybee (1994, p. 290).

De acordo com os usos de can, percebe-se sua metaforização, já que significados de origem, ligados à habilidade mental, são alterados, à medida que tal verbo, ao ligar-se a outro, permite a tonificação de sentidos relacionados à "capacidade geral do falante". Após esse primeiro processo, nota-se que o verbo generaliza-se novamente, passando a expressar uma possibilidade de raiz, ou seja, "condições gerais ligadas a possibilidades".

Para Lakoff e Johnson (1980), a essência da metáfora consiste em entender e experimentar uma coisa em termos de outra, como se vê nas relações entre dinheiro>tempo, uma vez que, a partir desta relação metafórica, todos os contextos que envolvem tempo estabelecem sentidos de perda, ganho, gasto e economia. O mesmo processo ocorre com a metáfora "discussão é guerra", pois, ao argumentar acerca de algo, o falante utiliza termos como "atacar", "contra atacar" "intimidar" e "defender", próprios das cenas bélicas. Assim, percebe-se o surgimento de novos usos a partir de outros mais sedimentados.

Trabalhos como os de Heine, Claudi e Hunnemeyer (1991) apostam na metáfora como um dos pilares da GR, pois há categorias que exprimem áreas mais concretas da experiência que fornecem formas para a expressão de campos conceptuais abstratos

$$
\begin{aligned}
\text { PESSOA }> & \text { OBJETO }>\text { PROCESSO > ESPAÇO > TEMPO > QUALIDADE } \\
& (\text { HEINE; CLAUDI; HUNNEMEYER, 1991, p. 157) }
\end{aligned}
$$


O arranjo acima permite entender que áreas mais concretas, como objetos, podem suprir a necessidade de expressão de conceitos mais abstratos, à sua direita, como processo, espaço, tempo ou qualidade.

Essas questões relativas à significação são sempre elencadas no conjunto de mudanças que podem evidenciar a GR. Por outro lado, Newmeyer (2001) discute a visão de GR não como um processo, mas como o "resultado de outros processos", que podem estar alinhados ou não, o que permite entendê-la como um "epifenômeno". Pode-se dizer que autores como Heine, Claudi e Hunnemeyer (1991) reconhecem que nem toda abstratização e metaforização são GR, pois há a tendência humana de construir noções abstratas a partir de noções concretas sem que isso seja sempre gramaticalização. No caso dos verbos cognitivos deduzir e calcular, porém, associam-se as alterações de significação, a serem mostradas, à GR, por haver mais uma mudança que pode ser relacionada a ela: a atuação do verbo de origem aos moldes do que se vê no comportamento de advérbios.

Tal comportamento é analisado na parentetização de I think, estudada por Thompson e Mulac (1991) como resultado de GR de expressão encaixadora. Os autores afırmam que, ao perder o complementalizador that, o verbo passa a se comportar como um acréscimo, um parêntese, sinalizador da opinião do falante, como em "It's just your point of view, you know what you like to do in your spare time, I think".

De acordo com os autores, a utilização da construção [sujeito+verbo] sem o complementalizador that (que) permite maior liberdade sintática, e o elemento passa a funcionar de forma semelhante a outras expressões epistêmicas, como o advérbio maybe, costumeiramente parentetizado. Segundo Schneider (2007, p. 2), expressões parentéticas são "inserções anexadas ao final da frase, de maneira semelhante aos advérbios". A natureza dos parênteses pode ser compreendida se tomada, também, a acepção de Jubran (2006), que os descreve como uma breve suspensão do tópico discursivo, que não constitui uma nova centração tópica e não afeta a coesão daquele dentro do qual ocorrem.

De forma semelhante, alguns autores brasileiros já lidaram com a GR de verbos, como Martelotta (1996), Freitag (2003), Casseb-Galvão (1999, 2000) e Gonçalves (2003). Optou-se por detalhar os que tratam de GR de verbos em condição de parênteses, assim, selecionou-se o de Casseb-Galvão (1999, 2000), que, ao investigar os diferentes usos do verbo achar, no português brasileiro, observou que, de um sentido mais pleno, o predicado passa por diferentes estágios de abstratização, apresentando uma trajetória composta por quatro diferentes acepções. O uso mais remoto de achar é relativo a encontrar algo concretamente, como em "Carlos achou a mochila". Um segundo funcionamento evidencia outra acepção, pelo fato de estar relacionada ao ato de apreciar, como em achar $_{2}$ : "eu acho que a televisão está se fazendo na medida" e achar ${ }_{2}$ "eu acho horrível aquela construção inacabada". Em achar ${ }_{3}$, identifica-se o "palpite", pois, em usos como "acho que quando se fala de estudos, fala-se em escola", percebe-se a marca de opinião 
do falante, o qual presume que, falando de estudo, fala-se também em escola. O quarto uso é caracterizado como parentético epistêmico quase asseverativo, pois permite ao falante apresentar ressalvas, a fim de relativizar a verdade do conteúdo afirmado.

Para Tavares e Freitag (2010, p. 104), os tipos de verbos podem ser relacionados a significados concretos, abstratos e genéricos, escala que pode servir de indício para o mapeamento de diferentes degraus de gramaticalização.

Outro estudo que relaciona parentetização e modalização é o de Gonçalves (2003)5. Ao analisar usos do verbo parecer, mostra que, de um sentido mais pleno, cujas acepções são "comparar" e "assemelhar", o verbo tem salientado significados ligados à evidencialidade e subjetividade, passando, assim, a se comportar como satélite atitudinal (epistêmico/evidencial), via parentetização. De acordo com Gonçalves (2003, p. 193), o trajeto desenvolvido pelo verbo achar referenda o que se propõe para parecer, pois, por mudança na estrutura da predicação, tais verbos dispensam o complementalizador que e se parentetizam ao lado de uma predicação completa.

Em Fortilli (2015), faz-se uma análise sobre expressões parentéticas com os verbos acreditar, imaginar e supor, a fim de analisar suas condições sociointerativas. Segundo a autora, "esses parênteses contam com um fator decisório para ocorrer: a necessidade de apresentar as informações e, ao mesmo tempo, resguardar-se de um total comprometimento com sua verdade" (FORTILLI, 2015, p. 1075). Tal consideração alinha-se às ideias de Neves (2013), que considera o fato de, em enunciados de primeira pessoa, o locutor legitimar espaço para registrar sua opinião e, situando seu enunciado no campo graduável do possível, confessar suas dúvidas e incertezas, a fim de ganhar a credibilidade do ouvinte. Ainda de acordo com a autora, a modalidade epistêmica envolve a atitude do falante e está intrinsecamente relacionada à fonte do conhecimento, com a qual o falante pode não estar comprometido totalmente.

\begin{abstract}
No extremo da certeza há um enunciador que avalia como verdadeiro o conteúdo de seu enunciado, apresentando-o como uma asseveração (afirmação ou negação), sem dar espaço para dúvida e sem relativização. Por outro lado, muitos enunciados oferecem um discurso com marcas do possível, e, no entanto, contêm elementos lexicais que, em princípio, confirmam certeza ao enunciado. Tais enunciados possuem elementos que implicam desconhecimento, ao lado de outros que implicam conhecimento por parte do falante. (NEVES, 2013, p. 172).
\end{abstract}

5 Em Gonçalves (2003), são apresentados cinco usos para o verbo parecer: parecer1: verbo pleno comparativo; parecer2: verbo suporte da predicação; parecer3: verbo encaixador de proposição (epistêmico/evidencial); parecer4: verbo em expressões, uso mais atual no português brasileiro e parecer5: satélite atitudinal (epistêmico/evidencial). 
Para a autora, a expressão de crença, opinião e posicionamento do falante pode aparecer tanto de forma taxativa quanto de forma relativizada, uma vez que os enunciados modalizados estão situados entre o certo e o provável.

Cognição e modalização são campos próximos, porém, não idênticos, e, através deles, certos verbos transitam graças às possibilidades de expressarem sentidos mais ou menos abstratos e de passarem por generalização de significados. Tal trânsito é o que será detalhado para calcular e deduzir.

\section{Metodologia}

Conforme mencionado, utilizou-se como fonte de dados o Córpus do Português (DAVIES; FERREIRA, 2006). Neste trabalho, não foi feita distinção entre o português brasileiro e o português europeu, uma vez que, de acordo com um olhar prévio sobre os dados, não há diferenças na parentetização dos verbos-alvo nas duas variedades. Um conjunto de ocorrências com deduzir e calcular como predicados foi construído, bem como um rol de dados com tais verbos parentetizados, procedimento adotado para a análise dos significados presentes em cada uso. Para o detalhamento das acepções dos verbos deduzir e calcular, foram selecionadas duas obras lexicográficas: Ferreira (2002) e Michaelis (2008) que, conjuntamente, possibilitaram matrizes semânticas para cada um. A partir das matrizes, observaram-se as acepções que mais se consolidam, sobretudo, no uso parentético, que foge ao que é típico para esses verbos.

\section{Análise dos verbos cognitivos deduzir e calcular no português}

Ao analisar as acepções do verbo calcular, foi possível confirmar que, para além das nuances ligadas à expressão de quantificação lógico-matemática, há aquelas ligadas à expressão de crença e opinião do falante:

computar

determinar valor

determinar por meio de cálculo

contar

ter em conta

raciocinar

avaliar

fazer cálculo

organizar visando lucros 
planejar

esperar

aceitar como possibilidade real

prever

estimar

fazer ideia de

imaginar

conjecturar

presumir

supor

Observa-se que calcular contempla as acepções "prever", "supor" e "conjecturar", que são características da expressão de modalidade epistêmica. Pela relação das ocorrências com o rol de significados, foram propostos dois campos-chave, que permitem a atuação em dois contextos distintos: raciocínio lógico matemático e atitude proposicional.

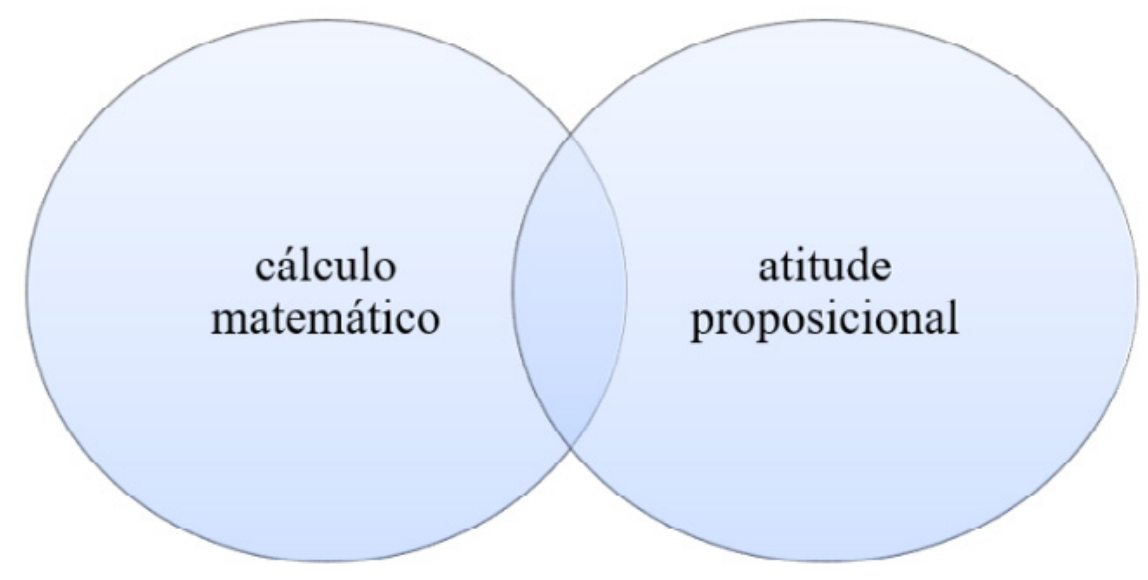

Figura 1. Domínio semântico do verbo calcular

Fonte: Elaboração própria.

Os usos de calcular nos contextos atestam a metaforização do verbo, pois, além do seu significado de origem, cujo funcionamento é proporcionado por acepções menos abstratas como "computar", "determinar valor", "contar" e "raciocinar", é forte a presença dos significados "prever", "aceitar como possibilidade real" e "presumir", acepções que são mais abstratas e gerais. 
De acordo com Lakoff e Johnson (1980), a função primária da metáfora é proporcionar uma compreensão parcial de um tipo de experiência em termos de outro, ou seja, a partir de um campo conceptual mais concreto, como o eixo do raciocínio lógico matemático, novos sentidos são desencadeados, proporcionando, no caso em tela, um intercâmbio entre a cognição e a modalidade epistêmica, como se vê a seguir:

(1). Caso não esteja correto, como faço para calcular inicialmente o preço de custo de aquisição da mercadoria (acdematos. wordpress.com $)^{6}$

(2). Tudo o que for chamado de ativo ou recebível entra nesta história. Calculo R\$ 140 bilhões. (190r:Br:Intrv:ISP)

Em (1), é possível observar nuances específicas de calcular, por se denotar processo ligado à quantificação e raciocínio matemático. Na ocorrência em (2), vê-se, mais uma vez, o uso típico, expressivo de quantificação de referentes numéricos. Já em (3) e (4), os objetos "quantificados" não consistem em entidades numéricas:

(3). Não é possível que tenhamos bife. Pela fumaça calculo o almoço que lá estão a fazer (18:Coelho:Conquista)

(4). Não conheço a ex-mulher do seu namorado, pela descrição calculo que seja desequilibrada (amacadeeva.clix.pt)

Nessas ocorrências, calculo relaciona-se a entes não-numéricos, como uma refeição e certo perfil emocional. Ainda não se vê, em (3) e (4), a parentetização, mas já se observa o favorecimento de significados não denotadores da especificidade de determinação de quantidade. "Estimar", "fazer ideia" e "imaginar", por sua vez, são significados presentes, pois o emissor inferiu informações. Pode-se dizer que a metáfora atua, nesses casos, permitindo que o falante, capaz de estabelecer processamento mental que mensura algo, isto é, calcula algo, possa também "mensurar" o almoço ou o equilíbrio mental de alguém, num entrelaçamento de acepções que vai das mais específicas para as mais gerais, o que desemboca na generalização,uma vez que o verbo calcular passa, assim, a atuar em um maior número de contextos.

Além da sinalização de postura epistêmica, calculo passa a contar com comportamento sintático diferente em (5) e (6):

6 Preservou-se a forma como as referências das ocorrências aparecem no Corpus do Português, a qual não é sistemática. 
(5). Opinião podem ter, calculo eu, os donos da verdade da política portuguesa, começando pelo primeiro-ministro... (altohama. blogspot.com)

(6). O seu artigo expõe um pensamento, calculo, generalizado. (ressabiator.wordpress.com )

Em (5) e (6), calculo adquire maior mobilidade sintática e apresenta-se na primeira pessoa do singular, característica fixa quando ele se parentetiza como modal. A atuação de calculo é, nesses casos, muito semelhante à tarefa cumprida por advérbios, e o seu estatuto de encaixador já não se encontra estabelecido, alteração que mobiliza questões categoriais implicadas em processos de GR. Ao contrário de comportar-se como núcleo, ao redor do qual os argumentos se organizam, no uso parentético, calcular é facultativo, pois é um modificador sentencial (CASTILHO, 2011).

A seguir, observam-se usos com o verbo deduzir, que também têm apresentado índices de abstratização, pois, de um sentido mais pleno, ligado à ação de "abater" e "reduzir", o verbo, já parentetizado, potencializa-se como indicador de opinião do falante diante de um conteúdo proposicional. Com base em Ferreira (2002) e Michaelis (2008), elencam-se as acepções:

\author{
abater \\ extrair \\ tirar \\ reduzir \\ enumerar \\ expor minuciosamente \\ diminuir \\ subtrair \\ descontar \\ tirar dedução \\ tirar como consequência \\ tirar de fatos ou princípios \\ propor em juízo \\ concluir \\ inferir \\ presumir
}


Percebe-se a presença, primeiramente, de acepções bastante concretas, como "expor minuciosamente", "reduzir" e "abater". Ao final, de maneira sugestivamente mais periférica, aparecem as nuances "inferir" e "presumir" que proporcionam usos mais abstratos. É importante notar que a nuance pela qual o verbo é mais conhecido pelos falantes é "tirar de fatos ou princípios", isto é, extrair uma ideia quando há uma espécie de "sinal" que torna válida uma dedução. Em sentido mais estrito, essa atitude costuma depender de acepções mais concretas, como ocorre no caso (7):

(7). Num ano o numero de vitimas supera largamente os que morreram em Berlim durante quase três décadas. Muitas delas mortas a tiro por milícias de voluntários que perseguem os emigrantes no deserto do Arizona como quem caça coelhos. Por alguns comentários aqui deixados, deduzo que para certas pessoas existem mortes injustificadas e mortes justificadas. (5dias.net)

Em (7), o falante afırma que sua dedução parte da evidência deixada por alguns comentários, ou seja, a ideia da existência de mortes justificadas e injustificadas é resultado das aferições que ele teve a partir dos indícios deixados anteriormente.

Nos usos em (8) e (9), também, é possível observar que o verbo deduzir revela uma atividade mental mais concreta, pelo fato de o processo envolvido situar-se no domínio da quantificação:

(8). O Diretor-Geral do DAER afirma que o traçado que interessou ao BID, de Santiago a Santa Tecla, com $90 \mathrm{Km}$ de extensão, se utiliza do percurso original da RST 377, até Jóia, com mais 23 Km, usando parte da BR 392, aproveitando a RS 522, em obras no trecho Jóia-Augusto Pestana, e o asfalto existente até ljuí. Segundo ele, as três grandes vantagens desse traçado são a menor distância até Jóia; a necessidade de uma ponte menor, e a possibilidade de o estado deduzir gastos com o BID. (19N:Br:PA)

(9). A Secretaria da Receita Federal ameaça tratar duramente quem deduzir despesas com educação... (19N:Br:PA)

Em (8), quando o falante declara "e a possibilidade de o estado deduzir gastos com o $B I D$ ", observa-se que deduzir denota uma atividade mental ligada a "reduzir", "diminuir" e "subtrair", mais concretas. Fato semelhante ocorre em (9), pois, ao afirmar "deduzir despesas com educação", o falante permite, por meio do verbo, a saliência da acepção "abater". 
Já as ocorrências (10) e (11) possibilitam a observação de outras acepções:

(10). Acho criticável que este inquérito, que cobre com grande acuidade o vasto campo de questões centrais da politica do ensino superior, a nível legislativo, não inclua o Estatuto da carreira docente. Deduzo que se vai manter a ideia de que é matéria de negociação exclusiva entre o Ministério e os sindicatos. (jvcosta.net)

(11). Euler, entendo sua situação. Deduzo que você leciona Sociologia muito bem, mas não é o caso de muitos professores... (CAT). (blogdoeulerconrado.blogspot.com)

Em (10) e (11), é possível recuperar sentidos mais abstratos, que denotam outras acepções, menos específicas. O falante, no uso em (10), ao afirmar que deduz a permanência da ideia que constitui matéria de negociação exclusiva, expressa uma atividade mais fluida, ligada a acepções como "presumir" e "inferir". Em (11), ocorre um processo semelhante, pois o falante expressa seu posicionamento, ao afirmar que deduz o fato de Euler lecionar Sociologia muito bem, sem que haja indícios mais basilares dos quais se tiraria uma dedução. Nota-se que evidenciar um processo mental específico é secundário, pois o que se cumpre com o verbo deduzir é a marcação de uma postura epistêmica.

Para além dos casos supramencionados, há os usos parentéticos de deduzir. Enquanto segmento independente, deduzir fixa-sena primeira pessoa do singular, do presente do indicativo e passa a não portar vínculo sintático explícito com a sentença. É o que se vê em (12) e (13):

(12). (...) como já sei que vc possui um grau de ignorância sobre biologia molecular e Teoria da Informação, alem de [deduzo] não saber distinguir causa inteligente em um evento/objeto, então não vou esperar que vc responda. (deusilusao.com)

(13). A minha pele é mista e, portanto, sensível (deduzo eu). (makedown88.blogspot.com)

Na sentença em (12), nota-se que, em contextos de parentetização, o verbo deduzir deixa de encaixar orações completivas e passa a funcionar como modificador. A afirmação "vc possui um grau de ignorância sobre biologia molecular e Teoria da Informação, alem de não saber distinguir causa inteligente em um evento/objeto" constitui uma sentença completa, cuja estrutura não depende do verbo deduzir como núcleo. O propósito do falante, 
pela utilização do parentético, é passar ao ouvinte a ideia de que tal afırmação deve ser interpretada como uma opinião, ou seja, não categórica. Por meio das ocorrências apresentadas, pode-se notar que o verbo deduzir atua em dois campos semânticos relacionados:

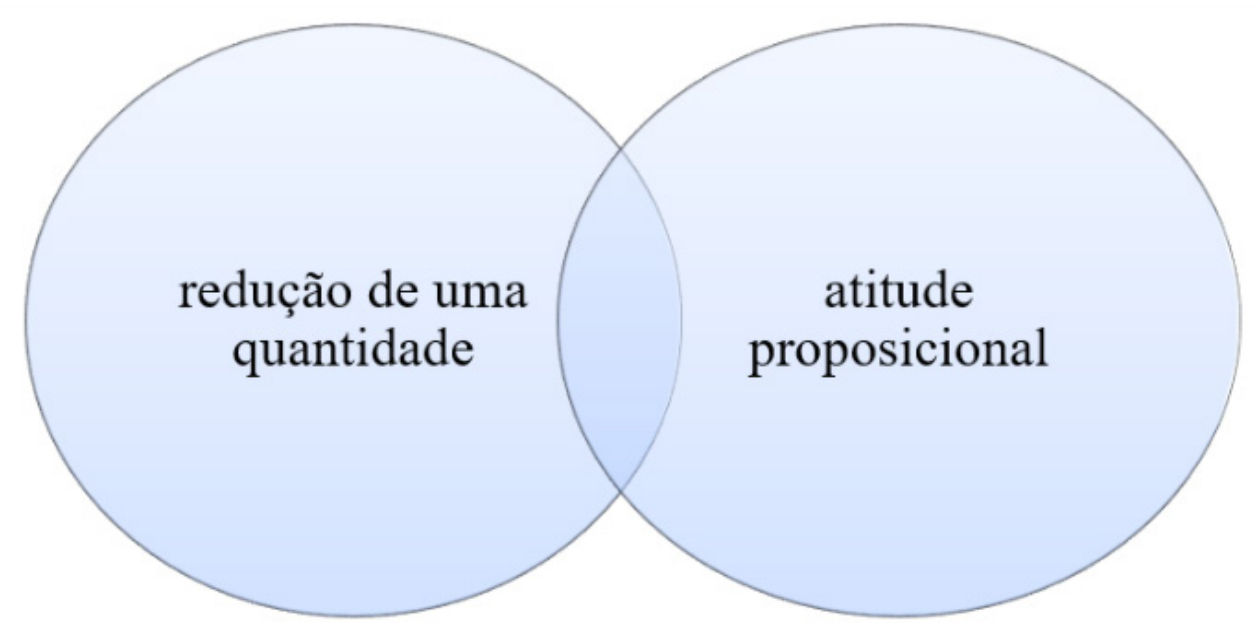

Figura 2. Domínio semântico do verbo deduzir

Fonte: Elaboração própria.

Os usos que expressam uma atividade mais concreta, ligada a ações como "reduzir", "descontar" e "extrair ideias", apresentam-se em um campo semântico mais ligado à cognição do falante, pois mostram uma atividade na mente sem, necessariamente, ativar significados modais. Por outro lado, as acepções "inferir" e "presumir" permitem a ocorrência de uma atividade ligada à atitude proposicional. Mais do que possibilitar ao falante demonstrar sua (in)certeza sobre algo, os parentéticos epistêmicos permitem que ele assinale, em um processo de negociação com o ouvinte, a forma como pretende que suas informações sejam recebidas. Segundo Fortilli (2015, p. 1074), "a natureza desses verbos revela que o falante tem uma postura defensiva, ou seja, ele anuncia o conteúdo no qual acredita, mas salienta seu comprometimento parcial com essa verdade".

Em deduzir, o processo de metaforização opera da seguinte forma: "presumir" e "inferir", mecanismos antes possibilitados pela presença de indícios que levavam a uma dedução, passam a não depender da existência de tais pistas. Assim, deduzo funciona mais para que o falante se mostre reticente quanto a uma informação que vai dar, já que é fonte dela e pode errar. Pode-se ver, de maneira associada, o processo de generalização de significados. 
Assim como calcular, deduzir parentetizado atua como um modificador sentencial, com desfavorecimento dos traços presentes em situações em que é verbo pleno/encaixador.

Nota-se a existência de apenas um pequeno grupo de verbos candidatos à parentetização com expressão de modalidade, o que motiva a observação do verbo somar, que, apesar de cognitivo, não é apto a funcionar aos moldes dos parentéticos aqui enfocados. Mesmo de maneira breve, é possível mostrar que, de acordo com Cunha (2010), somar origina-se do latim com as acepções: "operação de adição" e "resultado de uma adição". A partir de Ferreira (2002) e Michaelis (2008), notam-se as seguintes nuances de significado:

calcular o total

avaliar no todo

fazer a soma de

realizar adição

perfazer o total

totalizar

efetuar a operação da soma

concentrar esforços em uma causa comum

pôr-se junto a

juntar

acrescentar a um todo

agregar-se

incluir

adicionar

ter ou apresentar como soma

importar em

ser equivalente

sintetizar

resumir

reduzir

cifrar-se

Em somar, pelo fato de não haver acepção ligada ao sentido "macro" de possibilidade, a carga modal epistêmica não se apresenta. Sintaticamente, o predicado somar é 
caracterizado como verbo de dupla valência, uma vez que seleciona um argumento interno e um externo. Nota-se, pelas ocorrências em (14), (15) e (16),que a configuração sintática se mantém em todas as sentenças, sem parentetização.

(14). Na confecção da lista - de aprovados - começaram a haver alguns enganos - então o pessoal que entrava com mandado de segurança dizendo que foi contado pontos errados - enganos simples comuns - aritmética (às vezes) de somar o número de pontos - então eles entraram com mandado de segurança. (190r:Br:LF:SP)

(15). Um dos movimentos bandeirantes organizados chegou a percorrer as maiores distâncias de que se tem notícia entre todos os movimentos exploratórios continentais: as jornadas empreendidas por Antônio Raposo Tavares chegaram a somar distâncias percorridas de dez mil quilômetros... (19Ac:Br:Enc)

(16). Os órgãos encarregados da apuração precisam somar esforços. (190r:Br:Intrv:Pov)

Em (14), o verbo somar apresenta o seu sentido prototípico: "fazer a soma" e "realizar adição".Na ocorrência (15), as acepções mais salientes denotam atividades ligadas a ações como "totalizar", "realizar completamente" e "calcular o total", pois, ao afırmar: "as jornadas empreendidas por Antônio Raposo Tavares chegaram a somar distâncias", o processo mental envolvido articula fortemente ao último significado. O uso em (16) evidencia outro processo envolvido na soma, que é o fortalecimento de algo. Mesmo com tal acepção, menos concreta, o verbo não adentra a modalidade epistêmica, característica que se mostra inibidora da parentetização.

Retomando as acepções dos verbos deduzir e calcular, pode-se notar que, dentre as nuances semânticas que expressam uma atividade mental menos concreta, três proporcionam o fortalecimento da expressão de modalidade, em ambos: 


\section{calcular}

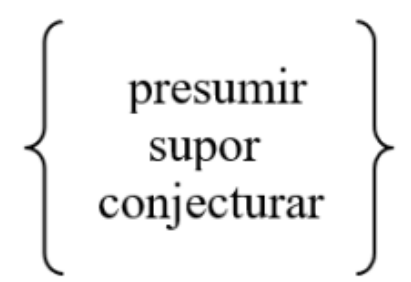

deduzir

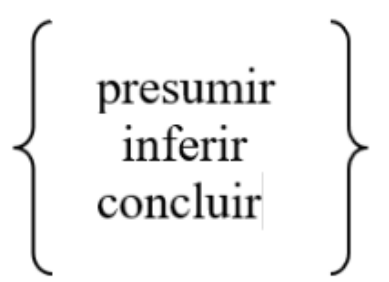

Tais acepções, por denotarem uma atividade mental baseada em atitudes proposicionais, isto é, que não se ancoram, necessariamente, em entidades e processos concretos e específicos, são fortalecidas quando o propósito é demonstrar a atitude do falante, além da negociação entre ele e o ouvinte, em termos de como o último deve encarar as informações. Sintaticamente, deduzir e calcular passam a apresentar um funcionamento próximo ao de advérbios/modificadores sentenciais, uma vez que, a exemplo do que Gonçalves (2003) delineou para o verbo parecer, vão se colocando para fora da estrutura da predicação, tornando-se menos integrados e tomando por escopo ou a oração toda ou, em alguns casos, apenas um constituinte dela.

\section{Considerações finais}

Por meio da análise, pode-se observar que, de fato, há acepções em calcular e deduzir mais ligadas à expressão de processos cognitivos, e outras que os encaminham mais fortemente para expressão da modalidade epistêmica. Ao serem utilizados em configuração parentética, acepções como "presumir", "supor", "conjecturar", "inferir" e "concluir" se evidenciam, e outras acepções menos abstratas tendem a não ficar aparentes. Nota-se, ainda, que tais elementos compartilham a acepção "presumir", que esboça o sentido de "informação não precisa, não exata", significado que parece ser o gatilho para que o falante reconheça que é possível a atuação dos dois verbos como "ressalvas" posicionadas fora da estrutura oracional. Nessa condição, eles ganham a mobilidade de modificadores sentenciais, por meio dos quais se materializa a postura de incerteza diante da proposição.

Observar como GR o que ocorre com calcular e deduzir é possível por duas percepções principais: o detalhamento de suas acepções, que tocam campos da atuação humana com diferentes graus de abstratização, o que amplia os contextos de uso, e o comportamento parecido com o de advérbio/modificador, que evidencia mudanças nos seus traços categoriais numa trajetória de ganho de gramaticalidade. 


\section{REFERÊNCIAS}

BYBEE, J. The evolution of Grammar: tense, aspect and modality in the languages of the world. London: The University of Chicago Press, Ltd., 1994. p. 281-302.

CASSEB-GALVÃO, V. O achar no português do Brasil: um caso de gramaticalização. 1999. Dissertação (Mestrado em Linguística) - Instituto de Estudos da Linguagem, Universidade Estadual de Campinas, Campinas, 1999.

CASSEB-GALVÃO, V. Mecanismos de análise sociolingüística e sua aplicação a um estudo de caso de gramaticalização. Revista de estudos da linguagem, Belo Horizonte, v. 9, n. 2, p. 73-82, jul./dez. 2000.

CUNHA, G. Dicionário etimológico da língua portuguesa. 4.ed. revista pela nova ortografia. Rio de Janeiro: Lexikon, 2010.

DAVIES, M.; FERREIRA, M. Corpus do Português: 45 milhões de palavras, 1300s-1900s, 2006. Disponível em: http://www.corpusdoportugues.org. Acesso em: 20 jul. 2018.

FERREIRA, A. B. H. O mini dicionário da língua portuguesa. 4.ed. rev. e ampl. do mini dicionário Aurélio. 7. impr. Rio de Janeiro, 2002.

FORTILLI, S. C. Parentetização de verbos de atividade mental no português falado e escrito. In: VII Simpósio Nacional de Estudos Filológicos e Linguísticos, 2015, Campo Grande. Revista Philologus, Suplemento Anais do VII SINEFIL, 2015. p. 1068-1078.

FREITAG, R. M. K. Gramaticalização e variação de acho (que) e parece (que) na fala de Florianópolis. 2003. Dissertação (Mestrado em Linguística) - Universidade Federal de Santa Catarina, Florianópolis, 2003.

GONÇALVES, S. C. L. Gramaticalização, modalidade epistêmica e evidencialidade: um estudo de caso no português do Brasil. 2003. Tese (Doutorado em Linguística) - Instituto de Estudos da Linguagem, Universidade Estadual de Campinas, Campinas, 2003.

GONÇALVES, S. C. L. Gramaticalização de construções com o verbo "parecer" no português brasileiro: de verbo pleno a satélite atitudinal. Veredas(UFJF), Juiz de Fora, v. 8, n.1/2, p. 195-214, 2004.

HALLIDAY, M. A. K. An Introduction to Functional Grammar. Baltimore: EdwardArnold, 1985. 
HEINE, B.; CLAUDI, U.; HUNNEMEYER, F. Grammaticalization: a conceptual framework. Chicago: University of Chicago, 1991.

HIMMELMANN, N. Lexicalization and grammaticalization: Opposite or orthogonal? In: HIMMELMANN, N.; WIEMER, B. (ed.). What makes Grammaticalization? A look from its Fringes and Components. Berlin: Mounton de Gruyter. 2004. p. 21-42.

HOPPER, P.; TRAUGOTT, E. Grammaticalization.Cambridge, UK: Cambridge University Press, 1993.

Folha de São Paulo. Disponível em: https://www.folha.uol.com.br/

JUBRAN, C. C. A. S Parentetização. In: JUBRAN, C. C. A., KOCH, I. G. V. (org.).Gramática do Português Culto Falado no Brasil: construção do texto falado. v. I. Campinas: Editora da UNICAMP, 2006. p. 301-357.

LAKOFF, G.; JOHNSON, M. Metaphors We Live By. Chicago: Chicago University Press, 1980.

MARTELOTTA, M. et al. Gramaticalização no português: uma abordagem funcional. Rio de Janeiro: Tempo Brasileiro. 1996.

MEILLET, A. L'evolution des formes grammaticales. In: MEILLET, A. Linguistique historique et linguistique générale. Paris: Klincksieck. 1912.

MICHAELIS. Dicionário escolar língua portuguesa. São Paulo: Melhoramentos,2008.

NEVES, M. H. M. Texto e gramática. 2. ed. São Paulo: Contexto, 2013.

NEWMEYER, F. J. Language form and language function. Massachusets: MIT Press, 2001.

SCHNEIDER, S. Reduced Parenthetical clauses as mitigators. A corpus study of spoken French, Italian and Spanish. Amsterdam: John Benjamin Publishing Company, 2007.

THOMPSON, S.; MULAC. A. A quantitative perspective on the grammaticalization of epistemic parenteticals in English. In: TRAUGOTT, E.; HEINE,B. (org.). Approaches to grammaticalization. v. 1. Philadelphia: John Benjamins Publishing Company, 1991. 